\title{
Modern Possibilities of Forensic Land and Soil Examinations Within the Civil and Criminal Law
}

\section{Pavlovska Nataliia}

PhD of Juridical Sciences, Associate Professor, Professor of Department of Civil Law and Process of the National Academy of Internal Affairs, Kiev, Ukraine ORCID ID 0000-0003-3311-0364_wwwpav@gmail.com

\section{Kofanova Olena}

PhD of Juridical Sciences, Associate Professor of Forensic Support and Forensic Expertise of the National Academy of Internal Affairs, Kiev, Ukraine ORCID ID 0000-0002-0919-7570 kofanova alena@ukr.net

\section{Kulyk Maryna}

PhD of Juridical Sciences, Associate Professor of Forensic Support and Forensic Expertise of the National Academy of Internal Affairs, Kiev, Ukraine ORCID ID 0000-0003-1373-6749 coolss777@ukr.net

\section{Strilets Halyna}

PhD of Judicial Sciences, Associate Professor of the Departament of Law of

Prydunai Branch of Private Jointstock Company «Higher Educational Institution of Interregional Academy of Personnel Management», Izmail, Ukraine

ORCID ID 0000-0002-1067-0820 galinastrelets2018@gmail.com

\section{Filipova Natalia}

Asistant of the Departament of Law of Prydunai Branch of Private Jointstock Company «Higher Educational Institution of Interregional Academy of Personnel Management», Izmail, Ukraine ORCID ID 0000-0001-7132-8343 filinatalja2310@gmail.com

\footnotetext{
Abstract

Forensic soil expertise is most commonly carried out in civil and criminal proceedings of the relevant issues. For this purpose, all types of soil formations, both naturally occurring and artificial, are used, wherein sometimes biological objects and human activity products (anthropogenic factor) constitute a major part. The
} 
multicomponentness and dynamism of soil-origin objects significantly complicate fulfilling the tasks set before expertise, including the fixation of its value. The problem of determining the classification category of forensic soil expertise remains controversial [1].

The subject of forensic soil expertise is factual evidences, circumstances of the case, established on the basis of special branches of knowledge: forensic science, forensic soil science and allied natural and engineering sciences: general soil science, geology, agrochemistry, and biology. Using the forensic soil expertise, a number of tasks may be solved by identifying: the fact that an object (subject) was in a specific location; the fact of contact interaction between any objects; the mechanism of soil adhering transference on various objects (clothes, shoes, household equipment, murder weapon or burglary tool, vehicle, etc.); spatiotemporal characteristics (time of individual soil layer transference, prescription of burial, etc.); certain negative circumstances, e.g., the noncorrespondence of the place of corpse discovery to the crime scene; the fact of environmental pollution.

Keywords: a general studies, i.e. a microscopic examination to identify various inclusions; determination of morphological characteristics; mineralogical study; study of the organic component; study of the biological component; analysis of the biochemical component of soils.

Introduction When commissioning forensic soil expertise, the solution of the following questions may be posed before it: 1 . What is the estimated cost of soils? 2. What is their recreational value? 3. What is the organic matter content? 4. What is the mineral content? 5. Are the soils contaminated with foreign substances? 6. Are there any soil adhering to the provided object-carriers, and what is their localisation? 7 . Whether the adhering found on the object-carrier are of soil-origin? 8. Are the provided soil samples suitable for identifying a specific location? 9. Did the soil adhering to the object-carriers previously belong to a particular location (place of murder, the discovery of a corpse, a vehicle)? Moreover, the location of a site, indicating its size and boundaries, is given; 10 . Does the soil have a characteristic composition indicating the source of its origin? 11. Were the objects provided for expertise in contact interaction, taking into consideration the adhering of soil microparticles to them? 12. What is the mechanism for the adhering formation? 13. What is the prescription of burial (contamination)? 14. Are the provided soil samples suitable for identifying a specific location?

The wording on the question concerning the homogeneity or similarity of a number of soil samples is too equivocal: if the questioned samples are of soil-origin, then they are always somewhat similar, and some part of them may be homogeneous [2]. To identify the presence of soil adhering to the object-carriers, the expert needs at least $0.1 \mathrm{~g}(100 \mathrm{mg})$ of the investigated material, to determine the generic (species) belonging of soils - at least $0.2-1 \mathrm{~g}$. The signs indicating the common origin of soils compared are both their generic (species) belonging and group one. 
Generic (species) belonging is determined in accordance with the classification accepted in the soil science. The group belonging of soils is understood as the nature of their use: the state of cultivation, anthropogenic factors (technogenesis - amelioration, the application of chemicals, fertilisers), the nature of the land, etc. It is not always possible to determine the temporal characteristics. This is impeded not only by the variability of the investigated object properties, but also by the violation of the soil packing rules, poor storage conditions, and delay in delivery for investigation. There are absolute (based on the plant development stages and season-dependent zoophases) and relative (according to the degree of putrefactive process development, moisture) temporal characteristics. In order to determine the place of origin of the soil adhering, palynological and diatom analyses should be used. The specifics of identification task solving during forensic soil examination deserves special attention [3].

The objects of the forensic soil examination are as follows: the topsoil of various locations, including the covering of basements, barns, garages, boiler houses, warehouse premises, partially constructed houses, backfilling of attics, walls; soil adhering to various object-carriers (items of clothing, footwear of a person, burglary tools, vehicles, etc.). The notion of an object of identification is highly specific for soils. It has been proved that soil adhering to the object-carriers sufficiently reflect the set of soil properties of the location from which they were transferred as a result of contact interaction. However, the question of "identity" or "equality" of different soils is incorrect methodically, since only a specific object can be equated. The fact of an object (suspect, vehicle) presence in a specific location from the point of view of the theory of forensic identification is considered as the identification of a specific location, which is carried out indirectly, i.e. through a comparative study of soil samples taken from this location and soil adhering from the object-carrier (the suspect's shoes, vehicle tire treads).

To identify a specific location, it is necessary to determine the degree of its individuality in relation to the neighbouring sites adjacent to it preliminarily, and to define its boundaries, i.e. to localise (concretising schematically and in the report) [4]. Localisation involves the demarcation of natural and/or artificial boundaries. The first is caused by naturally occurring factors and are linked to specific fixed relief features and vegetation (forest, meadow, river, gully, clove, etc.). The second is associated with human activities 
(embankment, vegetable garden, field, pit, etc.). If the site is localised, the belonging of the soil adhering to the object-carrier of this location is identified. If the crime scene is part of a territory that is relatively homogeneous in terms of soil and it cannot be localised, the task set before the expertise is to determine the general generic or group belonging of the soil adhering to the object-carrier (e.g., on the accused's clothes) and the soil from the crime scene. During the investigation of a road traffic accident (hereinafter referred to as RTA), soil particles left by the vehicle are found at the crime scene. In this case, the task of the expertise is the identification of a specific vehicle, which is carried out in a comparative examination of soil formations found on the road (or on the clothes of a hit pedestrian) and adhering that remained on the vehicle. In these cases, consideration must be given to the fact that soil adhering accumulate on the vehicle gradually, sometimes for a long time, when driving through locations with different topsoil. The set of features of the multi-layered formations in the presence of their unique complex allows identifying a specific vehicle [5]. Similarly, a comparative examination of soil particles, formations left by the subject's shoes on the object-carrier (in the footwear impression on the road, floor, windowsill, etc.), and soil adhering that remained on the subject's shoes is carried out. In this case, the object of identification is the subject's shoes. We shall consider the notion of reference and control soil samples. To conduct a comparative examination of the soil-origin substances, it is necessary to collect material evidence and soil samples.

Soil samples are divided into two types: reference samples (individual test portions), which are collected from the identification object (from a localised site, vehicle) or several suspected objects; control samples, taken to distinguish the object of identification from similar ones.

To demarcate the site that is identified, the control samples are taken from four sides outside it in the vicinity. Each control (mixed) soil sample consists of four to five samples taken within a radius of 5-10 $\mathrm{m}$ and packaged in one bag. If there are no natural or artificial boundaries of the site, i.e. there are difficulties in the visual localisation of the crime scene, samples should be taken at compass points and at a distance ranging from 25 to 200 metres (25-50-100-150 m) from the scene, without dividing them into reference and control. It is only possible to establish the degree of individuality and localise the crime scene with the help of control samples [6]. 
Thus, control samples allow establishing the degree of individuality of the identified object. If soil lumps were found on the roadbed, which probably separated from the vehicle at the moment of the accident, then reference samples are taken from different places of the suspected vehicle (from tires, bumpers, mud flaps, bridges). Control samples are collected from the road shoulder and from vehicles that have travelled the same route. If the subject's shoes are material evidence, the control samples will be taken from the place of residence, as well as the workplace of the owner of the shoes, to isolate from the entire mass of soil adhering that part, which does not concern the event [7].

There is a good reason to consider some options for a soil sample collection from a localised site. For example, the crime scene is a forest. The site localisation is carried out, taking into account the relief (slope, hill, gully, plain) and vegetation (its type or absence). These factors are clearly visible and in most cases, reflect the topsoil characteristics. The reference sample collection is carried out in a circle from the centre of the scene (4-5 samples from each). The number of circles is $2-3$, the distance between them ranges from 10 to 50 metres. The larger the site, the greater the distance should be between the circles. If the site is localised, control samples (4-5 pieces) are taken immediately outside of it, if not localised they are collected at 25-50-100-200 metres (in different directions).

If the crime scene is a meadow, localisation is easier because the vegetation characteristics can determine the degree of soil homogeneity. In this particular case, the vegetation characteristics depend only on the soil features, and in the forest, it is influenced by both illumination (the presence of trees, shrubs) and the relief pattern. Samples are collected in the same way as in the previous example. In both cases, plant samples should be taken from the crime scene. If this is a homestead plot or a vegetable garden, it is already localised by its own limits. Control samples are taken from an adjoining plot, a garden bed [8].

Such a crime scene as a basement of a house, an attic, a barn, a boiler house, or a partially constructed house is a clearly localised site, limited area within the frame of a building. Therefore, the localisation process involves dimensioning of the premises and describing its features: the presence of chambers and their number, dimensions; the cover surface colouring; the main components of the covering (sand, clay, brick, slag, other constructional materials); the covering condition (dry, damp, wet). The reference sample 
collection is carried out from different parts of the premises: directly from the crime scene, at the entrance to the premises, in each chamber, under the windows (one sample each). Control samples are taken immediately in front of the entrance to the basement, at some distance from the entrance (5-10 m) and similarly located ones near the premises.

If the crime scene is a flat, soil-contaminated household items (bedspreads, tablecloths, rugs), soil overlaying from the windowsill, from the floor (especially at the entrance to the premises, under the windows) are collected. As controls, samples are taken near the porch (communal entrance hallway), from the homeward path, or from the places where footwear impressions are detected in the sites located near the house. If the crime scene is the water bottom (lake, river), reference soil samples are taken from the bottom, the shore, near the drag marks, and control samples - from the opposite side of the reservoir, and if there is another reservoir nearby, then from it. Water samples are taken from the depth of the water reservoir. A road accident site is an object elongated longitudinally [9]. The road boundaries (moto roads, railways) are clearly defined transversely, but not longitudinally, therefore 4-5 reference samples are taken from the accident scene, and control samples are collected from the road shoulder, the right-of-way, the road itself at a distance of up to 200500 metres to one side and to the other from the centre of the accident scene.

If the crime scene is a pit, reference samples are taken from the surface at the edge of the pit, its bottom, walls, and control samples - outside the pit from sites with intact surface cover (from the surface and from a depth equal to the depth of the pit). Before collecting samples from the walls of the pit, one of them must be thoroughly cleaned of mixed soil. Then, samples are taken from the cleaned wall along the horizons, which are distinguished by colour, texture profile, assembly, and structure. If the soil is homogeneous throughout the profile and it is impossible to visually divide it into horizons, samples should be taken from a depth of 0-5, 10-15, 20-25 cm and so on down.

When digging a pit, the soil should be removed layer by layer, sifting it through a sieve with the holes ranging from $10 \mathrm{~mm}$ to $2 \mathrm{~mm}$ and noting what and in which layer was found (insects, plant remains, and other inclusions).

It is not allowed to mix reference samples from different horizons. On the packaging labels, it is necessary to indicate the sampling depth and horizon characteristics. Similarly, samples from the ravine are collected. 
The process of soil-origin object investigation may be divided into six stages: 1) a general studies, i.e. a microscopic examination to identify various inclusions (magnification $28 \mathrm{x}$ ); 2) determination of morphological characteristics; 3 ) mineralogical study (analysis of mineralogical components); 4) study of the organic component; 5)study of the biological component; 6) analysis of the biochemical component of soils.

The results of all investigation stages are summarised, defining the object's feature complex, which makes it possible, in particular, to localise the sites located at a distance of 50-100 m [10].

When describing plant particles, it is advisable to denote the plant type (herbaceous, arboreous), its part (lamina, stem, seeds, flower, bark, etc.), condition (fresh, faded, dry, at the stage of decomposition), and colour (green, brown).

Example: In soil samples from the crime scene and in the soil layer on the victim's clothes, experts found foreign inclusions - red, green and blue fibres. These fibres were the same as the fibres of the suspect's clothing and differed from the fibres of the victim's clothing. In addition, wood particles of coniferous species, characteristic of the crime scene, were found on the suspect's jacket. The set of established signs is individual. Not only the qualitative but also the quantitative composition of the inclusions can be specific. Example: The female corpse showing signs of violent death was discovered in a river on a littoral shelf. The suspect claimed that he parted from the victim at the bus stop and did not go beyond the highway. The determination of the soil morphological characteristics can be supplemented with the specification of: calcareousness; hygroscopic moisture content; $\mathrm{pH}$ value of the media. The hygroscopic moisture content is determined by drying the object (sample) to constant weight. The specified indicator depends on the texture profile and humus content. The method for determining soil calcareousness is not complex. A drop of $\mathrm{HCl}$ is applied to a glass slide, and portions of the soil substance are added to it. The reaction is observed in a magnifying glass (magnification 3.5x) and under a microscope. Depending on the calcareousness, boiling may be vigorous, weak, or absent altogether. It should be noted that the natural calcareousness is associated with the presence of limestones, mollusc shells, etc., the artificial one - carbonates $\mathrm{Ca}, \mathrm{Mg}, \mathrm{Mn}$, Fe, etc., introduced into the soil to improve fertility. 
The mineralogical study is carried out after separating each sample into clay and sandy fractions. The essence of the method of soil texture determining lies in the fact that both fractions are present in various proportions in almost all soils and their ratio is taken into consideration when the texture of the investigated samples is assessed. The geologicalmineralogical analysis is based on the soil sandy fraction stud, i.e. the physical, chemical and optical properties of minerals. The petrographic analysis is intended for the study of soil in thin sections, where the content and relative position of various components is determined. The identification and differentiation of soil samples by trace elements, which are rare in minerals, is performed by means of the emission spectral analysis. Luminescence analysis is sometimes used to diagnose minerals.

Then the organic component of the soil is investigated. The majority are humic substances, formed in the process of complex transformations of plant and animal residues. The elemental composition of organic substances, which is represented by C (50-60\%), H (3$6 \%), \mathrm{B}(30-40 \%), \mathrm{N}(2-6 \%)$, as well as $\mathrm{P}, \mathrm{S}, \mathrm{Se}, \mathrm{Fe}, \mathrm{Al}$ in certain proportions, is determined by the method of organo-elemental analysis. Electrophoresis and paper chromatography is used for the comparative study of the so-called humic acids - a complex mixture of organic substances of various compositions. Fractionation of humic acids is carried out by these methods. This permits to distinguish soil types using electrophoregrams and chromatograms by the number of zones, their location, colour intensity and the nature of the luminescence in UVS and visible light. The method for the ignition loss determining is indicative of the humus content in the soil. It is simple and express: ignition is carried out to constant weight. The IR spectroscopy method gives information about the atomic groupings that characterise the carbon skeleton of organic molecules, as well as about the functional groups in the molecules of humic substances. Spectral luminescence analysis according to the Shpolsky method makes it possible to identify polycyclic aromatic hydrocarbons (PAHs) in soils, which enter the soil with waste from industrial enterprises and transport. Qualitative and quantitative PAH spectra are used to differentiate soils.

The next step is to study the biological component of the soil: zoological, botanical, microbiological, palynological and diatom analyses, and the analysis of other single-celled algae. The palynological analysis involves determining the ratio of various pollen and spore types in the soil. Diatom analysis is effective in identifying reservoirs or wetted areas of soil 
since diatom algae - lower algae - exist in conditions of high moisture content. For these tests, 1-5 $\mathrm{g}$ of soil is enough.

Biochemical studies are presented by determining soil enzymatic activity.

Conclusions Thus, the local site must be considered as an element of the material situation of the accident, which was formed and exists under the influence of a large number of natural and random factors and is, therefore, characterised by a unique set of features, which creates significant opportunities for its identification [11]. It should be considered that the soil composition of the adhering may not be fully represented, since heavy coarse grains drop off, and small ones remain. The properly performed sample collection and the correct determination of the object of identification contribute to the efficiency improvement of soil examination to obtain both evidence and criminal intelligence information.

\section{References}

1. Forensics: Higher education textbook. / Edited by P.D. Bilenchuk. - K.: Pravo, 1997.

2. Averianova T.V., Belkin R.S., Korukhov Yu.H., Rossinskaia Ye.R. Forensics. Higher education textbook / Edited by R.S. Belkin. - M., 1999.

3. Fundamentals of Natural Science for Lawyers: Higher education textbook on the course "Concepts of Contemporary Natural Science" / Edited by E.R. Rossinskaia. - M., 1999.

4. A forensic examination of soil. A forensic examination of soil. URL: http://elar.naiau.kiev.ua/jspui/handle/123456789/1709

5. Forensics: Textbook for stud. of spec. Law universities / Edited by V.Yu. Shepitko. - K., 2001.

6. Forensics: Textbook. / Edited by P.D. Bilenchuk. - 2nd ed., revised and enlarged - K.: Atica, 2001. - 544 p.: il.

7. Saltevskyi M.V. Forensics (in the modern presentation): Textbook. - K.: Condor, 2005.

8. Kofanov A.V. Features of expert errors and some ways to prevent them during forensic ballistics examinations / Criminalistics and forensic examination: interdepartmental methodological collection / Ministry of Justice of Ukraine, Kyiv Scientific Research Institute of Forensic Expertise. - K., 2015. - Issue 60. - P. 275-287.

9. Kofanov A.V. Some aspects of the problematics of training forensic experts, their interaction with the executive management and their investigation evaluation / Forensic bulletin: scientific and practical collection / [Chief Editor V.V. Cherniei] / State Research Expert \& Forensic Centre of the MIA of Ukraine; NAIA. - K.: PC "Typography from "A" to "Z", 2013. - No. 2 (20). - P. 107-116.

10. Kofanov A.V. Disadvantages of psychological and legal (professional) training of a forensic expert as a prerequisite for the occurrence of expert errors / Forensic bulletin: 
scientific and practical collection / [Chief Editor V.V. Chernei] / State Research Expert \& Forensic Centre of the MIA of Ukraine; NAIA. - K.: PC "Typography from "A" to "Z", 2015. - No. 1 (23). - P. 72-79.

11. Kofanov A.V. The expert opinion or his analogue discussion (past and future) / Current issues of standardisation and accreditation of ballistics and weapons investigations: materials of the interdepartmental scientific-practical seminar (Kyiv, 12 January 2018) / Kyiv Scientific Research Institute of Forensic Expertise. - K., 2018. - P. 30-34. 